This is the first of two papers that examine clinical reasoning research in occupational therapy. It discusses the reasoning studies of the 1980s and 1990s, focusing on ethnographic and process-tracing approaches. From this critique, a need for an approach that acknowledges the experienced thinker's intuitive reasoning is identified. The second paper will present such an approach, based on social judgement theory, and demonstrate the first application of such a method in the field of occupational therapy.

\title{
Studying Oinical Reasoning, Part 1: Have We been Taking the Wrong Track'?
}

\author{
Priscilla A Harries and Clare Harries
}

\section{Views of the 1980s and 1990s}

In 1991, the American Journal of Occupational Therapy published a special issue on clinical reasoning. Many of the articles discussed the findings of the Clinical Reasoning Study sponsored by the American Occupational Therapy Association (AOTA) and the American Occupational Therapy Foundation (AOTF) (Fleming 1991a, 1991b, Mattingly 1991).

The AOTA/AOTF study used an ethnographic and action research approach: interviewing, observing and videoing 17 occupational therapists over a 2 -year period. It was the first major study to explore the reasoning strategies used by occupational therapists in their clinical work. The researchers identified reasoning 'tracks' or styles and linked these to reasoning strategies. The researchers had incorporated the work of Schön (1983), which placed value on reflection as a means of making implicit or tacit reasoning explicit (Mattingly and Fleming 1994). The findings of the 1991 papers have greatly influenced clinical reasoning studies in the field of occupational therapy.

\section{Reasoning tracks or styles}

The researchers in the AOTA/AOTF study argued that the specific style of occupational therapists' reasoning was dependent on the content of the task being thought about (Mattingly and Fleming 1994). For example, if a clinician thought about identifying an occupational dysfunction, a style named 'procedural reasoning' would be used (Fleming 1991b). Thought relating to a client's perspective of his or her needs would use 'interactive reasoning' and thought relating to a client's context and future potential would be termed 'conditional reasoning' (Fleming 1991b). The findings also identified other reasoning terminologies, such as 'narrative reasoning' (Mattingly 1991). Subsequent research on tracks of reasoning in occupational therapy has therefore recognised statements by task content (Ryan 1990, Alnervik and Svidén 1996, Fortune and Ryan 1996, Fossey
1996, Munroe 1996). This has sometimes appeared a little forced; for example, questions relating to future prognosis have been purposely asked to elicit 'conditional' reasoning (Ryan 1990, Alnervik and Svidén 1996).

\section{Reasoning strategies or processes}

The AOTA/AOTF study also searched for evidence of reasoning processes previously identified in the fields of psychology and medicine. Hypothetico-deductive strategies, whereby sets of hypotheses are generated and tested (Schmidt et al 1990), were thought to be used primarily in procedural reasoning and intuitive strategies were thought to be used primarily in interactive reasoning (Fleming 1991b).

Mattingly and Fleming may not have meant their findings, linking content with process, to be understood in such a purist light. Indeed, in their book published in 1994 (Mattingly and Fleming 1994), they were able to give greater depth to the understanding of the nature of the reasoning strategies used. However, the pervading links seem to have been grasped firmly and applied in occupational therapy research. As a result of this, many researchers have classified occupational therapists' clinical reasoning either by the style describing the thought content (for example, procedural) or by the reasoning strategies recognised in the thought processing (for example, hypothetico-deductive) (Ryan 1990, Alnervik and Svidén 1996, Hagedorn 1996, Munroe 1996).

To date, the ethnographic and information-processing approaches have provided the majority of methodologies used to study occupational therapists' clinical reasoning. Although these approaches were chosen to try to give a holistic understanding of thinking in context, they appear to be limited in terms of their ability to represent the holism of the thinking itself. This relates specifically to their limited ability to access reliably experts' well-practised thinking. These limitations are illustrated using the ethnographic study of Munroe (1996) and the information-processing study of Harries (1996) as examples. 


\section{Ethnographic study}

Munroe (1996) carried out an ethnographic qualitative study with 29 Scottish occupational therapists based in social work departments. The participants were field observed (by the researcher as a non-participant) during 83 home visits to see clients and carers. Field notes were kept by the researcher and given to the participants in order for key reflection points to be highlighted. The key reflection points were defined as times when they were aware of their thinking. The points were then the focus of in-depth interviews. Three parties checked the analysis of the interviews: focus groups of non-participants, the participants and selected externals. It was specifically the times of conscious thought that the researcher focused on in her data collection and analysis.

Munroe (1996) stated that she had expected to find greater evidence, in the field notes, of procedural reasoning; for example, the routine giving of equipment would be expected to follow the procedural reasoning track. However, there was minimal evidence of this. What was perhaps not considered was the fact that the repetitive nature of routine thinking tasks can cause thinking processes to become largely unconscious and intuitive (Abernathy and Hamm 1994). Therefore, once unconscious, the thinking would not be accessible to the researcher or the participant using this methodology. However, the authors suggest that it is highly probable that procedural reasoning had indeed occurred.

In the retrospective interviews, Munroe (1996) asked the participant to reflect on the thinking that had occurred during the home visits. She felt that, at this point, some clinical reasoning occurred, but admitted that the reasoning "came later - often much later - and usually in response to requests for interpretation or explanation of the thinking processes' (p200).

It could be said that it is difficult to assure the reliability of the retrospective content of reasoning. First, if earlier thinking has not initially been fully conscious, how then can awareness be regained at a later date? Second, the poor reliability of retrospective methodologies would be compounded by some inevitable difficulty in recall. Munroe (1996) did acknowledge concerns in using self-reflection as an accurate tool for accessing reasoning (Dreyfus and Dreyfus 1980).

\section{Information-processing study}

In 1996, a study of community mental health occupational therapists' reasoning was conducted to examine the factors influencing their acceptance of referrals (Harries 1996). The design was also drawn from the qualitative paradigm but, instead of using the AOTA/AOTF classifications and analysis, used methodologies from the informationprocessing approach.

Clinicians were asked to 'think aloud' as they read real referral letters. These think-alouds were followed immediately by an in-depth interview. It was found that the factors mentioned in the think-alouds were sometimes not acknowledged in the interviews. For example, when reading a referral a participant might have reflected on the worthiness of the referrer making the referral and yet, when interviewed, stated that he or she would view all referrers on an equal basis. There appeared to be a mismatch between the explicit reasoning processes in the think-alouds and those in the in-depth interviews. Researchers suggest that more weight should be placed on the findings of thinkalouds than on those of interviews (Elstein et al 1990). Although this may be based on some post hoc rationalisation, the think-alouds are thought to have more validity than interviews because they are concurrent rather than retrospective and, therefore, reduce issues such as accuracy of recall.

The findings drawn from vocalised think-aloud data showed several points of interest. The participants had their own personal method of framing the data. This was seen through the way in which they always attended to two or three particular factors, regardless of the referral information. In addition, the referral information influenced which other factors were attended to. For example, the second referral letter mentioned alcohol abuse, which led some of the participants to consider the appropriateness of the referral to their team's service. Compliance with team criteria overrode such issues as the needs stated in the reason for the referral.

Although the think-aloud accessed some points of interest, the think-aloud methodology did appear to have some weaknesses. First, the think-aloud did not access all the thinking that had occurred. For example, the participant would read the client's diagnosis but make no further comment; however, in the interview there would be lengthy explanation as to the necessary relevance of the client's diagnosis. This disparity may again be explained by the recognition that the experienced clinician uses minimal processing to make sense of familiar information (Abernathy and Hamm 1994).

Another weakness of the think-aloud related to the researcher's difficulty in understanding which vocalised thoughts were relevant to the decision task under study and which were not. For example, it was only through the interview that it became apparent that some thoughts had related to the decision to accept or reject the case (the decision under study) and others had related to issues such as treatment planning. It was not surprising that the decision to accept the case would be intertwined with other thinking tasks: other researchers have found that experienced clinicians do not use each stage of the occupational therapy process in a linear pattern (one stage following another) but, rather, use it in a much more complex way (Hagedorn 1996, Roberts 1996b). Had the think-aloud been used without the interview, the purpose of the reasoning would not have become apparent. The thinkaloud is a common method for examining reasoning, but in this instance it lacked the ability to identify those factors that were significant to the task (Newell and Simon 1972). These points illustrate that in this study some of the methodologies of information processing had difficulties in accessing accurate findings. 


\section{The cognitive continuum: a framework for reasoning}

The cognitive continuum theory (Hammond and Brehmer 1973) can be valuable in helping to understand the difficulties in accessing the full range of the reasoning processes. It describes a range of cognitive modes from intuitive to analytic, with quasi-experimental processing as a mid-point. This continuum is in contrast to the dichotomy often created between processes that are implicit and unconscious and those that are explicit and fully conscious.

In more intuitive reasoning, strategies such as pattern recognition and heuristics (rules of thumb) are used. Cues (information) are immediately linked to known patterns (Larkin 1979). It is a largely unconscious, rapid and automated process: it is 'non-recoverable' (Hammond and Brehmer 1973).

Hypothetico-deductive reasoning is a slower, more analytical method of thinking that is characterised by conscious awareness. We use cues to generate possible hypotheses and test these hypotheses with further cue use.

It is clear that the process used is influenced by the level of expertise. When we are less practised in a cognitive task we tend to use analytical processing, but when we are more practised in a reasoning task, and the information is familiar, we tend to use intuitive strategies (Hammond and Brehmer 1973, Benner 1984, Elstein et al 1990). In addition, the cognitive continuum identifies the influence of task characteristics on reasoning strategy. Task characteristics, such as stability and availability of task information, have a strong influence on the possible types of cognitive processing (Shanteau 1992). It may well be that different types of reasoning task, involving different content, also have different task characteristics and are associated with different types of cognitive mode.

\section{Influence of expertise}

Within the specific task of diagnosis formation, there are differences between novices' and experienced practitioners' reasoning strategies (Elstein et al 1990). Researchers (Schmidt et al 1990) have found that experts in familiar situations do not usually display explicit hypothesis testing. As experts have the advantage of previous experience, they have developed a store of 'scripts' (Abernathy and Hamm 1994). If a client has a familiar problem, the expert can use pattern matching to trigger the direct automatic retrieval of an appropriate script. Therefore, he or she uses a rapid and automatic form of processing which is recognised as intuitive reasoning (Abernathy and Hamm 1994).

Roberts (1996a) and Robertson (1996) recognised the influence of expertise on occupational therapists' reasoning. The AOTA/AOTF study had focused mainly on hypotheticodeductive strategies in problem-identification tasks. Elstein et al (1978) were the first to identify that hypotheticodeductive reasoning was used in diagnosis formation in medicine. It was therefore not surprising that occupational therapists looked for hypothetico-deductive reasoning in identifying (diagnosing) occupational dysfunctions (Fleming 1991a).

Roberts (1996b), however, demonstrated that this did not show the full picture: reasoning would vary according to the level of expertise and the nature of the task. In her research, 38 practitioners wrote down their thoughts immediately after reading three referral letters. Although some of the reasoning might have been lost before the participants began to write down their thoughts, some interesting findings were made. Some practitioners initially used rapid formulations of the issues involved (pattern matchers/heuristic reasoners). Others appeared to have less experience to draw on: they searched for cues and reasoned using various hypotheses, sometimes not reaching any specific formulation. The rapid formulators did show evidence of hypothetico-deductive reasoning when considering some aspects of the case. In these instances, they may have been less familiar with the information. This would concur with the view that reasoning strategies result from the interaction between the experience of the practitioner and the nature of the task.

Robertson (1996) found that occupational therapy students lacked the ability to make the link between a client's problems and his or her treatment goals. She called for a method to access clinicians' intuitive thought, a method that could make these implicit links accessible.

\section{Methodological issues in accessing intuitive thinking}

The reason that early research into clinical reasoning has not accurately accessed the full range of reasoning, from intuitive to analytic, appears to be due to methodological issues. Elstein et al (1978) used process-tracing approaches to analyse the verbal protocols of clinicians as they thought out loud. Roberts (1996a) also advocated a process-tracing approach. In the AOTA/AOTF ethnographic study, intuitive reasoning was at least nominally identified, but the method by which it was elicited was described as 'difficult to map' (Fleming 1991b). No details of the ways in which the mapping was attempted were stated.

The ethnographic and information-processing methods rely heavily on the reasoner's awareness of how information is being used to make judgements. They are therefore limited in their ability to access the more unconscious, rapid and unrecoverable reasoning at the intuitive end of the continuum (Ericsson and Simon 1980).

With regard to accessing the thinking of experts, verbal reports are now recognised by some as inefficient and misrepresentative of expertise (Hoffman 1987). Concurrent verbalisations at best get to the content of working memory or the information attended to (but not necessarily how it is used) and retrospective verbalisations (sometimes while viewing the scenario in a video recording) are prone to forgetting and post hoc rationalisation (Ericsson and Simon 1980).

From this perspective, expert occupational therapists' thinking has not been fully investigated. If we wish to 
understand how experienced clinicians make decisions, we must find ways of accessing their thinking effectively. More specifically, we must find ways of understanding the intuitive reasoning strategy. The decision analysis school of thought is unsuitable for studying clinical reasoning because it attempts to suggest how decisions should be made before decisions take place. It is therefore not descriptive of clinical decisions as they are actually made in practice (Hersey and Baron 1987). From an examination of the literature relating to the development of expertise in clinical reasoning and from their own research into clinicians' clinical reasoning strategies, the authors advocate that occupational therapists complement the ethnographic and information-processing approaches with the judgement analysis approach. Judgement analysis has been successfully applied to other clinical fields but has yet to be used in occupational therapy. The methodology of social judgement theory (Cooksey 1996), known as judgement analysis, is proposed as an effective avenue for studying clinical reasoning in occupational therapy.

\section{A study using judgement analysis}

A last study (Kirwan et al 1986), now to be discussed, demonstrates that information-processing methods can be inferior to those of the new approach, namely judgement analysis. It also confirms the lack of awareness that experienced practitioners have when trying to report verbally the factors that influence their clinical decision making.

The study, conducted by researchers at The Royal London Hospital, examined 89 rheumatologists' policies for prescribing anti-inflammatory medication. As the rheumatologists saw patients, they were asked to record five cues (pieces of information), such as early morning stiffness, as well as the medication that they then prescribed. This was used to identify the prescribing policies that they actually employed in practice. They were then asked to give an indepth interview to explain how they assessed patients. This was to simulate teaching their stated policies to medical students.

The policies that the rheumatologists used in practice were compared with the policies that they thought they had used (stated policies). The stated policies were found to be poor predictors of actual policies used $\left(\mathrm{R}^{2}=34 \%\right)$. The cue information recorded in the clinics was then used to create a set of 50 paper patients (including a replicate set of 20 to test for test-retest reliability). The clinicians then tried prescribing for the paper patients and the results were examined. The requirement for individuals to make decisions on a large number of relevant problems is a methodology of judgement analysis. The judgements over real patients correlated well with those over paper patients $\left(\mathrm{R}^{2}=88 \%\right)$ but, again, on paper patients the stated policies were poor predictors of actual policies used $\left(\mathrm{R}^{2}=39 \%\right)$.

One explanation for this is that, owing to the unconscious processing that occurs at high levels of expertise, clinicians are not able to describe their practice policies accurately. It appears that the more experienced we are, the less able we are to tell what we know (Nisbett and Wilson 1977, Hoffman 1987). The teaching of students may have reflected textbook theories on prescribing, from which the practitioners had originally learnt. In practice, their learning may have developed mainly from discussions with colleagues (Wyatt 1991). If the information spread is not true to the experts' practices then the learning is less effective than it could be. It is important that we consider methods that are able to tap into less verbalisable processing and find out not just the pieces of information used but the weighting and combination of these cues as used by experienced clinicians. Judgement analysis can allow this to be done.

\section{Limitations of current methodologies}

To summarise, the methodologies used so far to understand occupational therapists' clinical decision making are lacking in several respects:

1. It is likely that experts' thinking is largely automatic: processing has become reduced to a minimum (Ericsson and Simon 1980). Some factors are also used unconsciously and are not made explicit during data collection (Doherty and Kurz 1996). Concurrent verbal reports are sometimes inappropriate for the clinical setting, so retrospective reports are recorded after the situation has occurred. This unfortunately allows for some memory loss of significant factors, which therefore leads to missing data.

2. Hypothesising about policy judgements used in clinical decisions has been found to be an unreliable reflection of the judgement policies in actual use (Nisbett and Wilson 1977, Evans et al 1995). Owing to the focus of qualitative research, the data have usually been collected from small numbers of subjects on a small number of scenarios. The ability to generalise about an individual's decision making or indeed about the profession's policies on decision making has not been intended. Another methodology is necessary to identify the wider picture. One essential reason for establishing the policies of clinical experts is to ensure that education is truly evidence based. Lack of sufficient data on expert policy has limited the potential for training occupational therapy novices. Case scenarios have been used to help novices build up their own theoretical experience of clinical examples (Abernathy and Hamm 1995). However, as the case scenarios have been developed from information-processing methodologies (commonly using retrospective reports), the qualitative information used for training may lack the reliability and validity that the judgement analysis approach could yield.

\section{Conclusion}

Reliable and valid knowledge of how a profession's experts identify and use information is necessary to train students in good decision making. It is important to consider alternative methods of understanding clinical decisions to see if they offer more useful or complementary approaches. Judgement 
analysis, the methodology of social judgement theory, will be described in part two: 'Studying clinical reasoning: applying the methodology of judgement analysis'.

\section{References}

Abernathy C, Hamm RM (1994) Surgical scripts: master surgeons think aloud about 43 common surgical problems. Philadelphia: Hanley and Belfus.

Abernathy C, Hamm RM (1995) Surgical intuition: what it is and how to get it. Philadelphia: Hanley and Belfus.

Alnervik A, Svidén G (1996) On clinical reasoning: patterns of reflection on practice. Occupational Therapy Joumal of Research, 16, 98-110.

Benner P (1984) From novice to expert: excellence and power in dinical nursing practice. Menlo Park: Addison-Wesley.

Cooksey RW (1996) Judgement analysis: theory, methods and applications. London: Academic Press.

Doherty ME, Kurz EM (1996) Social judgement theory. Thinking and Reasoning, 2, 109-40.

Dreyfus HL, Dreyfus SE (1980) Mind over machine. Oxford: Blackwell.

Elstein AS, Shulman LS, Sprafka SA (1978) Medical problem solving: an analysis of dinical reasoning. Cambridge, MA: Harvard University Press.

Elstein AS, Shulman LS, Sprafka SA (1990) Medical problem solving: a 10year retrospective. Evaluation and the Health Professions, 13, 5-36.

Ericsson KA, Simon HA (1980) Verbal reports as data. Psychological Review, 87, 215-51.

Evans JS, Harries C, Dennis I, Dean J (1995) General practitioners' tacit and stated policies in the prescription of lipid lowering agents. British Journal of General Practice, 45, 15-18.

Fleming MH (1991a) Clinical reasoning in medicine compared with clinical reasoning in occupational therapy. American Journal of Occupational Therapy, 45(11), 988-96.

Fleming MH (1991b) The therapist with the three-track mind. American Journal of Occupational Therapy, 45(11), 1007-14.

Fortune T, Ryan S (1996) Applying clinical reasoning: a caseload management system for community occupational therapists. British Journal of Occupational Therapy, 59(5), 207-11.

Fossey E (1996) Using the Occupational Performance History Interview (OPHI): therapists' reflections. British Journal of Occupational Therapy, 59(5), 223-28.

Hagedorn R (1996) Clinical decision making in familiar cases: a model of the process and implications for practice. British Journal of Occupational Therapy, 59(5), 217-22.

Hammond KR, Brehmer B, eds (1973) Quasi-rational and distrust: implications for international conflict. Human judgement and social interactions. New York: Rineholt and Winston.

Harries PA (1996) A study to identify, in the field of mental health, the factors influencing occupational therapists' decision making as to whether or not to accept a referral. Unpublished MSc thesis. Exeter: University of Exeter.
Hersey JC, Baron J (1987) Clinical reasoning and cognitive processes. Medical Decision Making, 7, 203-11.

Hoffman RR (1987) The problem of extracting the knowledge of experts from the perspective of experimental psychology. A Magazine, 53-67.

Kirwan JR, Chaput de Saintonge DM, Joyce CR, Holmes J, Currey HL (1986) Inability of rheumatologists to describe their true policies for assessing rheumatoid arthritis. Annals of Rheumatic Diseases, 45, 156-61.

Larkin JH, ed (1979) Information processing and science instruction. Cognitive process instruction. Philadelphia: Franklin Institute.

Mattingly C (1991) The narrative nature of clinical reasoning. American Journal of Occupational Therapy, 45, 998-1005.

Mattingly C, Fleming MH (1994) Clinical reasoning: forms of inquiry in a therapeutic practice. Philadelphia: FA Davis.

Munroe $H$ (1996) Clinical reasoning in community occupational therapy. British Journal of Occupational Therapy, 59(5), 196-202.

Newell A, Simon H (1972) Human problem solving. Englewood Cliffs: Prentice Hall.

Nisbett R, Wilson T (1977) Telling more than we can know: verbal reports on mental processes. Psychological Review, 84, 231-59.

Roberts AE (1996a) Approaches to reasoning in occupational therapy: a critical exploration. British Journal of Occupational Therapy, 59(5), 233-36.

Roberts AE (1996b) Clinical reasoning in occupational therapy: idiosyncrasies in content and process. British Joumal of Occupational Therapy, 59(8), 372-76.

Ryan S (1990) Cinical reasoning: a descriptive study comparing novice and experienced occupational therapists. Unpublished MSc thesis. New York: Columbia University.

Schmidt HG, Norman GR, Boshuizen HPA (1990) A cognitive perspective on medical expertise: theory and implications. Academic Medicine, 65, 611-21.

Schön D (1983) The reflective practitioner: how professionals think in action. New York: Basic Books.

Shanteau J (1992) Competence in experts: the role of task characteristics. Organizational Behavior and Human Decision Processes, 53, 252-266.

Wyatt J (1991) Use and sources of medical knowledge. Lancet, 338, 1368-72.

\section{Authors}

Priscilla A Harries, DipCOT, MSc, SROT, Lecturer, Department of Health Studies, Brunel University, Osterley Campus, Borough Road, Isleworth, Middlesex TW7 5DU.

Clare Harries, BSc, PhD, Research Fellow, formerly at the Department of Psychology, University College London, and now based at the Centre for Decision Research, Leeds University Business School, Maurice Keyworth Building, University of Leeds. 